\title{
The Impact of Obesity on Sexual Functions and Dyadic Consensus in Patients with Obesity
}

\author{
Sevda Bag, $\mathrm{MD}^{1}$ and Feray Akbas, $\mathrm{MD}^{2}$
}

\begin{abstract}
Background: Obesity is a chronic disease with several co-morbidities that increase morbidity and mortality and decrease quality of life. Psychopathologies are an important group of co-morbidities. In this study, it was aimed to search for the presence of depression and sexual dysfunction in patients with obesity, examine impact of obesity on marital adjustment, and highlight those important problems that are usually overlooked.

Methods: Fifty patients who were seen in the obesity outpatient clinic in a random month as case group and gender-matched 50 healthy individuals as control group were included in the study. The inclusion criteria were body mass index (BMI) $\geq 30 \mathrm{~kg} / \mathrm{m}^{2}$ and having a sexual partner. The exclusion criteria were having psychiatric/ mental or any other chronic illness, using medication that would affect sexual functions, and alcohol/substance abuse. After recording the sociodemographic data, patients were asked to take three internationally validated questionnaires: The Arizona Sexual Experience Scale (ASEX), Dyadic Adjustment Scale (DAS), and Beck Depression Inventory (BDI). Results were analyzed using SPSS.

Results: Fifty patients with obesity as case group and 50 normal weight healthy persons as control group were included in the study. BMI and BDI score were significantly higher in the case group than in the control group. DAS score was lower in the case group for consensus and affectional expression than the control group but there was no difference for satisfaction, cohesion, or total score between the groups. ASEX score was higher in the case group than in the control group.

Conclusion: Patients with obesity have dyadic consensus problems with their partners. Their excessive weight causes distress and difficulty in expressing their feelings and usually results in marital problems and depression. Evaluation of the patient with a multidisciplinary approach in obesity centers will allow patients to be analyzed in every aspect of obesity including these issues and contribute to the success of the treatment.
\end{abstract}

Keywords: depression, obesity, sexual disorders, anxiety, dyadic consensus

\section{Introduction}

$\mathrm{O}$ BESITY IS DEFINED AS ABNORMAL or excessive fat accumulation that presents a risk to health by the World Health Organization (WHO). The ratio of fat mass to lean body mass is increased to cause weight to exceed the limits determined according to the height. ${ }^{1}$

Obesity is classified using body mass index (BMI). It is now accepted as a disease beyond being a cosmetic problem. Thus, obesity-related pathologies are a matter of concern. ${ }^{2}$ Although physical co-morbidities of obesity are well established, its association with psychopathologies is less explored and needs to be addressed better. ${ }^{3}$
Anxiety, depression, and sexual dysfunction usually accompany obesity and decrease quality of life seriously. ${ }^{4,5}$ Sexual health is an important part of human life in both men and women, but expression of sexual problems or diagnosis of these pathologies is not as easy as physical pathologies. Dyadic consensus, dyadic satisfaction, dyadic cohesion, and affectional expression are terms to describe the quality of marriage. Despite present researches about obesity and sexual dysfunction, obesity and marital quality are still unexplored.

In this study, it was aimed to search for the presence of depression and sexual dysfunction in patients with obesity, examine impact of obesity on marital adjustment, and highlight those important problems that are usually overlooked.

Departments of ${ }^{1}$ Psychiatry Clinic and ${ }^{2}$ Internal Medicine Clinic, University of Health Sciences, Istanbul Training and Research Hospital, İstanbul, Turkey. 


\section{Materials and Methods}

Fifty patients who were seen in the obesity outpatient clinic in a random month as case group and gender-matched 50 healthy individuals as control group were included in the study.

The inclusion criteria were BMI $\geq 30 \mathrm{~kg} / \mathrm{m}^{2}$, having a sexual partner, and positive informed consent.

The exclusion criteria were BMI $\leq 30 \mathrm{~kg} / \mathrm{m}^{2}$, having psychiatric/mental or any other chronic illness, using medication that would affect sexual functions, and alcohol/ substance abuse.

After recording the sociodemographic data, the patients were asked to take three internationally validated questionnaires that were The Arizona Sexual Experience Scale (ASEX), Dyadic Adjustment Scale (DAS), and Beck Depression Inventory (BDI).

The ASEX: this is a five-item self-rating scale that quantifies sex drive, arousal, vaginal lubrication/penile erection, ability to reach orgasm, and satisfaction from orgasm. Each question is scored between 1 and 6 and total score would be 5-30. This test has national validity and reliability approval in our country. According to this test, the patient has sexual dysfunction if a total score of $\geq 19$ or any one item with a score of $\geq 5$ or any three items with a score of $\geq 4$ is found. ${ }^{6}$

DAS: the test is developed by Spanier. The scale's Turkish validity and reliability study was conducted by Fişloğlu and Demir. ${ }^{7}$ The test evaluates marital quality testing dyadic satisfaction, dyadic consensus, dyadic cohesion, and dyadic affectional expression. ${ }^{8}$ Total score is the sum of all scores gained from answers from each part of the questionnaire and it is between 0 and 151 . Higher scores indicate better marital quality.

BDI: BDI is an objective self-rated scale that evaluates the level of somatic, emotional, motivational, and cognitive symptoms seen in depression. ${ }^{9}$ It contains 21 items on a 4-point scale from 0 (symptom absent) to 3 (severe symptoms). The total score is achieved by adding the highest ratings for all items and it is between 0 and 63 . Higher scores indicate greater symptom severity. The national adaptation of the test is made by Hisli. ${ }^{10}$

Statistical method: statistical analysis was performed using SPSS 22.0 for Windows program. Descriptive statistics were reported as mean, standard deviation, median, minimum, maximum, frequency, and percentage values. Distribution of variables was tested with Kolmogorov $\mathrm{Si}$ mirnov test. Quantitative independent data analysis was made with Mann-Whitney $U$ test. Qualitative independent data analysis was made with chi-square test. The statistical significance level was regarded as $P<0.05$.

This study was approved by the Ethics Committee of Istanbul Training and Research Hospital (1879/2019). All participants provided written informed consent. All procedures performed in the study were in accordance with the 1964 Helsinki Declaration.

\section{Results}

The mean age was $42.6 \pm 9.7$ years for the case group and 33.9 \pm 9.1 years for the control group. Mean age was higher in the case group than in the control group $(P<$ 0.05 ), but there was no significant difference for gender, marital status, or number of children between case and control groups $(P>0.05)$. Level of education was lower in the case group than in the control group $(P<0.05)$. Employment rate was higher in the case group than in the control group $(P<0.05)$. The duration of marriage was longer in the case group than in the control group $(P<$ 0.05) (Table 1).

BDI score was higher in the case group than in the control group $(P<0.05)$. DAS score was lower in the case group for consensus and affectional expression than in the control group $(P<0.05)$, but there was no difference for satisfaction, cohesion, or total score $(P>0.05)$ between the groups. ASEX score was higher in the case group than in the control group $(P<0.05)$ (Table 1, Figs. 1 and 2).

Table 1. Results of Case and Control Group

\begin{tabular}{|c|c|c|c|c|c|}
\hline & \multicolumn{2}{|c|}{ Case group } & \multicolumn{2}{|c|}{ Control group } & \multirow[b]{2}{*}{$P$} \\
\hline & Mean $\pm S D / \mathrm{n}(\%)$ & Median & Mean $\pm S D / \mathrm{n}(\%)$ & Median & \\
\hline Age & $47.4 \pm 11.8$ & 49.0 & $45.2 \pm 9.7$ & 48.0 & $0.237^{\mathrm{a}}$ \\
\hline $\begin{array}{l}\text { Gender } \\
\text { Women } \\
\text { Men }\end{array}$ & $\begin{array}{l}13(17.1) \\
63(82.9)\end{array}$ & & $\begin{array}{c}5(16.7) \\
25(83.3)\end{array}$ & & $0.957^{\mathrm{c}}$ \\
\hline Body mass index $\left(\mathrm{kg} / \mathrm{m}^{2}\right)$ & $37.3 \pm 5.4$ & 37.0 & $22.7 \pm 2.1$ & 23.0 & $0.000^{\mathrm{a}}$ \\
\hline Waist circumference & $117.3 \pm 11.6$ & 118.0 & $86.8 \pm 10.5$ & 90.0 & $0.000^{\mathrm{a}}$ \\
\hline Hip circumference & $127.1 \pm 12.6$ & 128.0 & $95.5 \pm 9.8$ & 97.5 & $0.000^{\mathrm{a}}$ \\
\hline Fat mass & $42.8 \pm 6.2$ & 44.3 & $27.1 \pm 7.5$ & 26.2 & $0.000^{\mathrm{a}}$ \\
\hline 6 gait speed & $6.0 \pm 1.2$ & 6.0 & $5.8 \pm 1.0$ & 5.9 & $0.459^{\mathrm{a}}$ \\
\hline Chair stand & $11.0 \pm 2.7$ & 10.6 & $9.0 \pm 1.8$ & 9.7 & $0.000^{\mathrm{a}}$ \\
\hline Hand grip & $25.3 \pm 28.0$ & 18.8 & $20.1 \pm 8.2$ & 18.0 & $0.436^{\mathrm{a}}$ \\
\hline Calcium & $9.4 \pm 0.4$ & 9.4 & $9.4 \pm 0.4$ & 9.3 & $0.333^{\mathrm{a}}$ \\
\hline Vitamin D & $16.8 \pm 7.5$ & 16.8 & $19.5 \pm 11.0$ & 18.8 & $0.148^{\mathrm{b}}$ \\
\hline Parathormone & $58.7 \pm 22.0$ & 55.0 & $51.7 \pm 19.2$ & 51.9 & $0.271^{\mathrm{a}}$ \\
\hline
\end{tabular}

${ }^{\mathrm{a}}$ Mann-Whitney $U$ test.

${ }^{\mathrm{b}} t$ test.

${ }^{\mathrm{c}}$ Chi-square test.

$\mathrm{SD}$, standard deviation.

The significant values are written in bold italics. 
FIG. 1. DAS score results of case and control groups. DAS, Dyadic Adjustment Scale.

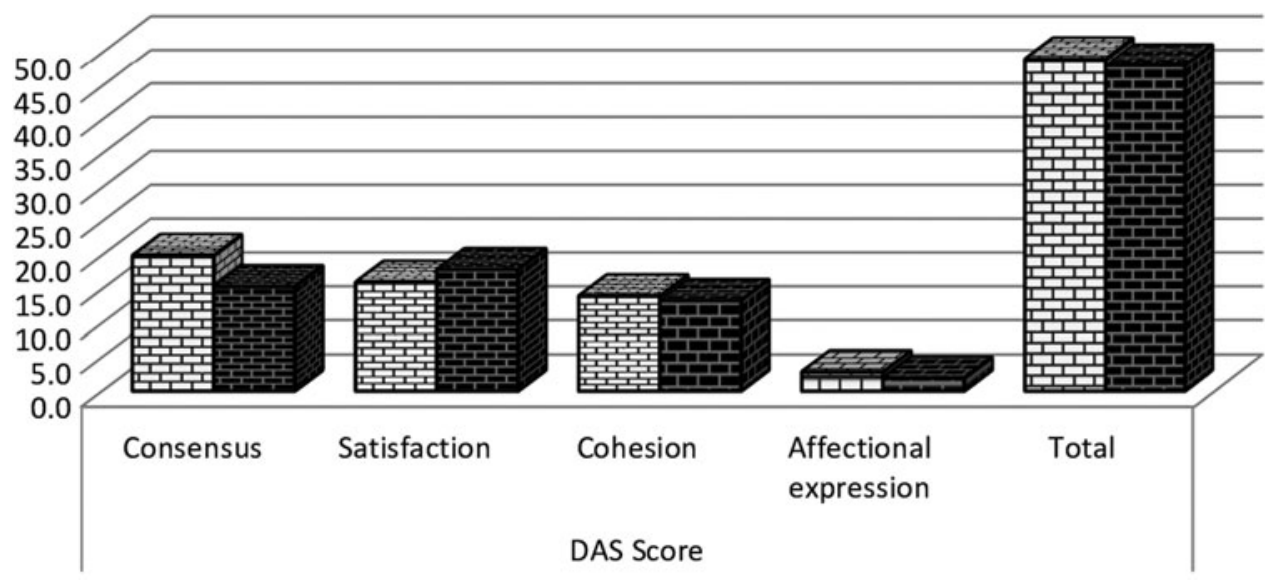

DControl group $\mathbf{E}$ Case group

Sexual health is an important determinant of quality of life and body weight/image is one of the main components affecting sexual life. ${ }^{21}$ Kaneshiro et al. showed that increasing obesity levels negatively affected sexual life in women in their study with 6690 women with obesity living in United States. $^{22}$ Our study also showed that obesity caused sexual problems between partners when compared with people with normal weight. Kolotkin et al. conducted a series of studies to find that obesity was a risk factor for the degree of dysfunction in sexual life. However, in obesity, sexual dysfunction could also be related to other psychiatric problems, including low self-esteem and low self-body image instead of being only directly related to obesity. ${ }^{23}$ High rates of depression concomitantly with sexual dysfunction found in our study in persons with obesity support this idea. In the literature, it is emphasized that sexual dysfunction in women is more related to low self-body image than BMI. Studies defend that women with obesity avoid sexual intercourse because they think their body is not attractive for their partners. Thus, the source of the problem is "avoiding" sexuality rather than sexual dysfunction. ${ }^{24}$

Sexual activity is decreased in men with obesity. Erectile dysfunction and other sexual abnormalities such as decreased sexual desire or sexual intercourse satisfaction seen in men with obesity benefit from weight loss. ${ }^{25,26}$ Body weight seems to be the most important part of body image and it is important to analyze the impact of obesity on sexual impaired performance in life that results in high rates of depression.

FIG. 2. ASEX score and BDI results of case and control groups. ASEX, Arizona Sexual Experience Scale; BDI, Beck Depression Inventory.

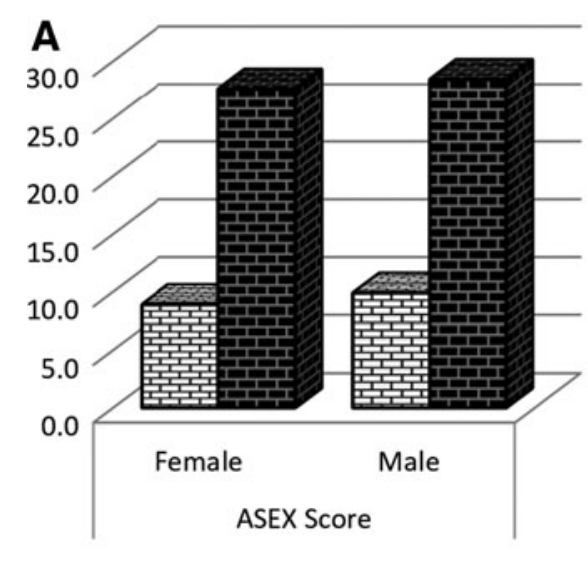

- Control group ECase group

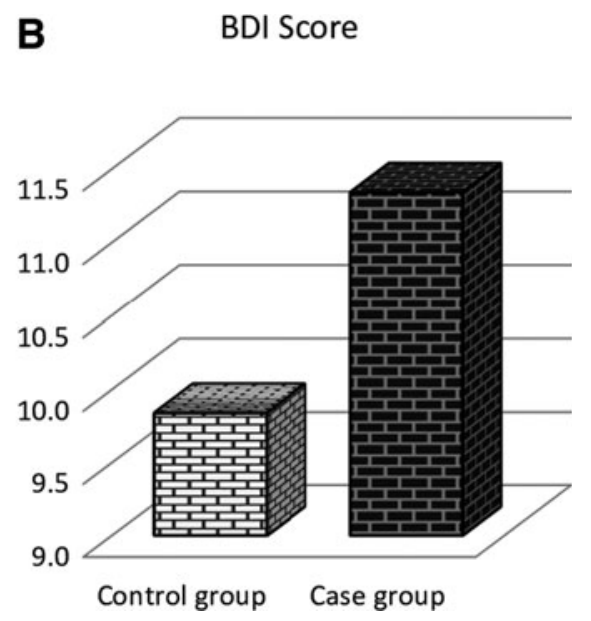


functions in both men and women while evaluating a patient with obesity.

Obesity affects relationship quality with partners and causes marital problems. ${ }^{27}$ Although we did not find a significant difference in total DAS score in case and control groups, subgroup DAS score for consensus and affectional expression was lower in the case group than in the control group, predicting that people with obesity could not express their feelings well and had difficulty to agree on subjects with their partners. There are several studies about sexual dysfunction in obesity, but the data are limited about dyadic consensus. $^{28-30}$ Thus, this study is one of the few studies highlighting the importance of the subject. Increasing BMI causes not only sexual problems but also increases depression rates in married couples, ${ }^{31}$ and marriage quality is improved in different aspects with weight loss. ${ }^{32}$ As obesity causes marital problems, marital problems can increase the risk for obesity and create an unavoidable circle. ${ }^{33}$

In contrast, dyadic consensus benefits weight loss. It was found that in women with type 2 diabetes, dyadic consensus scores at the beginning of treatment predicted changes in BMI over time, with better problem solving and higher relationship satisfaction at baseline related to steeper decreases in BMI across treatment. ${ }^{34}$ Along with obesity, dyadic consensus scores are decreased in many other situations such as urinary incontinence, ${ }^{35}$ receiving infertility treatment, ${ }^{36}$ cancer, especially breast cancer, ${ }^{37,38}$ depression and other psychiatric disorders, ${ }^{39,40}$ and many other life-limiting illnesses. ${ }^{41}$ A dyadic reintegration model is suggested to support dyads facing life-limiting illness. This model includes three adaptation processes of comprehension, creative adaptation, and reintegration for couples to achieve a better communication and relationship. ${ }^{41}$

\section{Conclusion}

Obesity is one of the major causes of depression, sexual function impairment, and diminished marital quality. Thus, health care providers should include questions about these subjects using motivational interview techniques and prevent those problems to remain overlooked. Psychosocial support should be a part of obesity treatment. The partner of the patient should be included in the treatment and counseling of couples should be applied when necessary. Treatment of obesity does not only intend improvement in physical health but also psychological health and quality of life. Obesity centers with multidisciplinary approach seem to provide the best solution to all aspects of health care to patients with obesity.

\section{Author Disclosure Statement}

No conflicting financial interests exist.

\section{Funding Information}

No funding was received for this article.

\section{References}

1. World Health Organization (WHO). Obesity and overweight. Accessed at www.who.int/mediacentre/factsheets/ fs311/en on April, 2019.
2. Guh D, Zhang W, Bansback N, et al. The incidence of comorbidities related to obesity and overweight: A systematic review and meta-analysis. BMC Public Health 2009;9:88.

3. Rajan TM, Menon V. Psychiatric disorders and obesity: A review of association studies. J Postgrad Med 2017;63: 182-190.

4. Yaylali GF, Tekekoglu S, Akin F. Sexual dysfunction in obese and overweight women. Int J Impot Res 2010;22: 220-226.

5. Mannucci E, Petroni ML, Villanova N, et al. Clinical and psychological correlates of health-related quality of life in obese patients. Health Qual Life Outcomes 2010;8:90.

6. Soykan A. The reliability and validity of Arizona sexual experiences scale in Turkish ESRD patients undergoing hemodialysis. Int J Impot Res 2004;16:531-534.

7. Fışıloğlu H, Demir A. Applicability of the dyadic adjustment scale of marital quality with Turkish couples. Eur $J$ Psychol Assessment 2000;16:214-218.

8. Prouty AM, Markowski EM, Barnes HL. Using the Dyadic Adjustment Scale in marital therapy: An exploratory study. Family J Counsel Ther Couples Families 2000;8:250257.

9. Beck AT, Steer RA, Brown GK. Manual for the Beck Depression Inventory-II. San Antonio, TX: Psychological Corporation 1996.

10. Hisli N. Validity and reliability of depression scale in university students (Journal in Turkish) (Psikoloji Dergisi) (Journal of Psychology) 1989;23:3-13.

11. Global strategy on diet, physical activity and health diet, nutrition and the prevention of chronic diseases report of the joint WHO/FAO expert consultation. WHO Technical Report Series, No. 916. Accessed at https://www.who.int/ dietphysicalactivity/publications/trs916/intro/en/ on April, 2019.

12. Mitchell NS, Catenacci VA, Wyatt HR, et al. Obesity: Overview of an epidemic. Psychiatr Clin North Am 2011; 34:717-732.

13. Segula D. Complications of obesity in adults: A short review of the literature. Malawi Med J 2014;26:20-24.

14. WHO. Controlling the global obesity epidemic. Accessed at https://www.who.int/nutrition/topics/obesity/en/ on April, 2019.

15. Hofmann B. Obesity as a socially defined disease: Philosophical considerations and implications for policy and care. Health Care Anal 2016;24:86-100.

16. Taskin Yilmaz F, Karakoc Kumsar A, Demirel G. The effect of body image on sexual quality of life in obese married women. Health Care Women Int 2019;40:479492.

17. Jung FU, Luck-Sikorski C. Overweight and lonely? A representative study on loneliness in obese people and its determinants. Obes Facts 2019;17:1-8.

18. Kersbergen I, Robinson E. Blatant dehumanization of people with obesity. Obesity 2019;27:1005-1012.

19. Speed MS, Jefsen $\mathrm{OH}, \mathrm{B} \emptyset$ rglum $\mathrm{AD}$, et al. Investigating the association between body fat and depression via Mendelian randomization. Transl Psychiatry 2019;9:184.

20. Himmelstein MS, Puhl RM, Quinn DM. Overlooked and understudied: Health consequences of weight stigma in men. Obesity 2019;27:1598-1605.

21. Poggiogalle E, Di Lazzaro L, Pinto A, et al. Health-related quality of life and quality of sexual life in obese subjects. Int J Endocrinol 2014;2014:847871.

22. Kaneshiro B, Jense JT, Carlson NE, et al. Body mass index and sexual behavior. Obstet Gynecol 2008;112:586-592. 
23. Kolotkin RL, Binks M, Crosby RD, et al. Obesity and sexual quality of life. Obesity 2006;14:472-479.

24. Lipowska M, Lipowski M. Narcissism as a moderator of satisfaction with body image in young women with extreme underweight and obesity. PLoS One 2015;10:e126724.

25. Di Vincenzo A, Busetto L, Vettor R, et al. Obesity, male reproductive function and bariatric surgery. Front Endocrinol 2018;9:769.

26. Xu J, Wu Q, Zhang Y, et al. Effect of bariatric surgery on male sexual function: A meta-analysis and systematic review. Sex Med 2019;7:270-281.

27. Sobal J, Rauschenbach BS, Frongillo EA. Body weight and relationship quality among women: Associations of obesity and underweight with relationship communication, conflict, and happiness. Int J Sociol Family 2009;35:25-44.

28. Bajos N, Wellings K, Laborde C, et al. Sexuality and obesity, a gender perspective: Results from French national random probability survey of sexual behaviours. BMJ 2010;340:c2573.

29. Yaylali GF, Tekekoglu S, Akin F. Sexual dysfunction in obese and overweight women. Int J Impot Res 2010;22: 220-226.

30. Larsen SH, Wagner G, Heitmann BL. Sexual function and obesity. Int J Obes 2017;31:1189-1198.

31. Wickrama T, Bryant CM. Association between body mass index and depressive symptoms of African American married couples: Mediating and moderating roles of couples' behavioral closeness. J Family Issues 2012;33:613618.

32. Rand CSW, Kuldau JM, Robbins L. Surgery for obesity and marriage quality. JAMA 1982;247:1419-1422.

33. Kiecolt-Glaser JK, Jaremka L, Andridge R, et al. Marital discord, past depression, and metabolic responses to highfat meals: Interpersonal pathways to obesity. Psychoneuroendocrinology 2015;52:239-250.

34. Yorgason JB, Sandberg JG, Weinstock RS, et al. The importance of relationship processes for lowering BMI over time in women with type 2 diabetes in a randomized controlled trial. Obes Res Clin Pract 2019;13:599-601.

35. Gumussoy S, Kavlak O, Donmez S. Sexual function and dyadic adjustment in women with urinary incontinence. Pak J Med Sci 2019;35:437-442.

36. Zeren F, Gürsoy E, Çolak E. The quality of life and dyadic adjustment of couples receiving infertility treatment. Afr $J$ Reprod Health 2019;23:117-127.

37. Wittmann D. Emotional and sexual health in cancer: Partner and relationship issues. Curr Opin Support Palliat Care 2016;10:75-80.

38. Kayser K, Acquati C. The influence of relational mutuality on dyadic coping among couples facing breast cancer. J Psychosoc Oncol 2019;37:194-212.

39. Aggarwal S, Grover S, Chakrabarti S. A comparative study evaluating the marital and sexual functioning in patients with schizophrenia and depressive disorders. Asian J Psychiatr 2019;39:128-134.

40. Arciszewska A, Siwek M, Dudek D. Dyadic adjustment among healthy spouses of bipolar I and II disorder patients. Psychiatr Danub 2017;29:322-329.

41. Ahluwalia S, Reddy NK, Johnson R, et al. Dyadic model of adaptation to life-limiting illness. J Palliat Med 2020 [Epub ahead of print]; DOI: 10.1089/jpm.2019.0444.

Address correspondence to: Sevda Bag, MD

Department of Psychiatry Clinic University of Health Sciences Istanbul Training and Research Hospital Org. Abdurrahman Nafiz Gurman Cad.

Etyemez, Samatya Istanbul 34098 Turkey

E-mail: sevdabag@yahoo.com 